\title{
A IMPORTÂNCIA DO LUGAR PARA A ESTRUTURAÇÃO E A EXPANSÃO DO CIRCUITO ESPACIAL PRODUTIVO DE CELULOSE EM MATO GROSSO DO SUL ${ }^{1}$
}

\section{THE IMPORTANCE OF THE PLACE FOR THE STRUCTURATION AND EXPANSION OF THE CELLULOSE PRODUCTIVE SPACIAL CIRCUIT IN MATO GROSSO DO SUL}

\author{
Leandro Reginaldo Maximino LELIS ${ }^{2}$ \\ Celso Donizete LOCATEL $^{3}$
}

\begin{abstract}
Resumo: Este artigo objetiva evidenciar a importância do lugar para a estruturação e a expansão do circuito espacial produtivo de celulose em Mato Grosso do Sul. Para isso, serão apresentados oito fatores que comprovam essa ideia. Entende-se que abaixa densidade técnica das atividades agropecuárias pré-existentes, a disponibilidade de terras de menor preço, a concentração fundiária, a mão de obra barata, a pré-existência de uma base florestal, a localização geográfica, a disponibilidade hídrica e, principalmente, a atuação do Estado são fatores que, em conjunto, possibilitaram a estruturação e a expansão do circuito espacial produtivo de celulose no estado pesquisado, evidenciando a importância do lugar para os estudos sobre os circuitos espaciais produtivos.
\end{abstract}

Palavras-chave: lugar; circuito espacial produtivo; celulose; Mato Grosso do Sul.

\begin{abstract}
This article aims to evidence the importance of the place for the structuration and expansion of the cellulose productive spacial circuit in Mato Grosso do Sul.For this, eight factors will be presented that prove this idea. It is understood that the low technical density of pre-existing farming activities, the availability of lower priced land, the land concentration, cheap labor, pre-existence of a forest base, geographical location, water availability andmainly, the State's performance are factors that, together, enabled the structuring and expansion of the cellulose productive spacial circuit in the researched state, evidencing the importance of the place for studies on productive spacial circuits.
\end{abstract}

Keywords: place; productive spacial circuit; cellulose; Mato Grosso do Sul.

\section{Introdução}

A expansão do circuito espacial produtivo de celulose em Mato Grosso do Sul ocorreu durante a década de 2000. Em poucos anos, o estado pesquisado tornou-se um dos principais produtores e exportadores de celulose do país. Atualmente, existem duas empresas produtoras de celulose no estado, a Fibria e a Eldorado Brasil.

\footnotetext{
1 As reflexões presentes neste artigo fazem parte da pesquisa de doutorado intitulada "O circuito espacial produtivo de celulose e o uso do território em Mato Grosso do Sul”, realizada pelo primeiro autor sob a orientação do segundo.

${ }^{2}$ Doutor pelo Programa de Pós-Graduação e Pesquisa em Geografia da Universidade Federal do Rio Grande do Norte (PPGe/UFRN). E-mail: sukko51@ hotmail.com.

${ }^{3}$ Professor do Programa de Pós-Graduação e Pesquisa em Geografia da Universidade Federal do Rio Grande do Norte (PPGe/UFRN). E-mail: celso.locatel@gmail.com.
} 
A Fibria inaugurou sua primeira linha de produção de celulose no município de Três Lagoas, extremo Leste de Mato Grosso do Sul, em 2009. Posteriormente, em 2017, entrou em operação sua segunda linha de produção, também localizada em Três Lagoas. Somadas, as duas linhas de produção possuem capacidade para produzir 3,05 milhões de toneladas de celulose por ano.

A Eldorado Brasil, empresa pertencente ao Grupo JBS, inaugurou sua fábrica de celulose, que possui capacidade para produzir 1,7 milhão de toneladas anuais, em 2012, também em Três Lagoas. Embora tenha iniciado a instalação da segunda linha de produção, as obras foram suspensas devido aos escândalos envolvendo o Grupo JBS.

Esses grandes projetos de celulose possibilitaram a expansão do circuito espacial produtivo de celulose em Mato Grosso do Sul, especialmente no Leste do estado, contudo somente foram possíveis devido à combinação de oito fatores que, juntos, possibilitaram as condições ideais para o circuito pesquisado no estado em questão. Nesse contexto, esta pesquisa pretende evidenciar a importância do lugar para a estruturação e a expansão do circuito espacial produtivo de celulose em Mato Grosso do Sul.

Destarte, procurar-se-á evidenciar que a baixa densidade técnica das atividades agropecuárias pré-existentes, a disponibilidade de terras de menor preço, a concentração fundiária, a mão de obra barata, a pré-existência de uma base florestal, a localização geográfica, a disponibilidade hídrica e, principalmente, a atuação do Estado configuram-se como fatores fundamentais para a estruturação e a expansão do circuito espacial produtivo de celulose em Mato Grosso do Sul.

Além do resumo, desta introdução e das considerações finais, este artigo possui mais dois itens. O primeiro apresenta breves considerações acerca do conceito do lugar e sua importância para os estudos sobre os circuitos espaciais de produção. O segundo exibe detalhadamente os oito fatores, destacando suas principais características, bem como as interrelações existentes, já que estes fatores não ocorrem isoladamente, pelo contrário, notam-se relações de complementaridade entre eles.

\section{O conceito de lugar e sua importância para os estudos dos circuitos espaciais de produção}

A conjuntura contemporânea evidencia que a globalização não foi capaz de homogeneizar o espaço global. Pelo contrário, verifica-se que as singularidades dos lugares permanecem. Todavia, os lugares não se encontram isolados, pois estão em contato constante com o mundo. Nessa perspectiva, Santos (2006) aponta que a modernização contemporânea possibilitou a mundialização os lugares em virtude da ampliação do contato com o mundo.

No período atual, marcado pela globalização, a ordem global busca impor uma única racionalidade a todos os lugares. Todavia, o lugar se apresenta como forma de resistência a essa ordem global, pois nem todos os elementos globais são incorporados, tendo em vista que elementos locais são mantidos, fazendo com que o lugar possua a sua própria racionalidade (SANTOS, 2006). Assim, para Santos (2006, p. 231): “cada lugar é, ao mesmo tempo, objeto de uma razão global e de uma razão local, convivendo dialeticamente".

$\mathrm{O}$ desenvolvimento das telecomunicações ampliou o conhecimento mundial em relação às possibilidades dos lugares, fazendo com que sua escolha para o desenvolvimento de determinada atividade seja mais precisa. As empresas, então, têm a seu dispor informações extremamente detalhadas sobre os lugares que as interessam. É dessas informações sobre as possibilidades dos lugares, inclusive, que depende o sucesso das empresas. Por isso, nenhuma empresa se instala antes de uma análise minuciosa sobre o lugar em que desenvolverá suas atividades. Nesse sentido, para Santos (2006, p. 167): "é desse modo que os lugares se tornam 
competitivos. $\mathrm{O}$ dogma da competitividade não se impõe apenas à economia, mas, também, à geografia".

As especificidades dos lugares fazem com que as empresas se instalem em um lugar e não em outro, visando maior rentabilidade de suas atividades. Segundo Santos (2006, p. 166): "os lugares se distinguiriam pela diferente capacidade de oferecer rentabilidade aos investimentos. Essa rentabilidade é maior ou menor, em virtude das condições locais [...]".

O circuito espacial produtivo de celulose, por exemplo, poderia ter se expandido para qualquer outra fração do território brasileiro, entretanto, quando se analisam os fatores, notase que a forma em que estão organizados em Mato Grosso do Sul foi fundamental para a expansão do circuito pesquisado neste estado.

Vale salientar que o circuito espacial produtivo de celulose tem se expandido para outras unidades da federação nos últimos anos, como, por exemplo, para o Maranhão, mas não com a mesma magnitude da expansão verificada em Mato Grosso do Sul. A magnitude econômica alcançada pelo circuito espacial produtivo de celulose em Mato Grosso do Sul, nos últimos anos, evidencia que a combinação dos fatores existentes nesta fração do território possibilitou as condições ideais para sua estruturação e expansão, tanto é que a Fibria e a Eldorado Brasil, as duas principais empresas desse circuito instaladas na região, anunciaram a ampliação de suas fábricas em Três Lagoas.

As condições propícias para o circuito espacial produtivo de celulose fizeram com que se inserisse, em menos de uma década, o Mato Grosso do Sul entre os maiores produtores de eucalipto e de celulose do Brasil, além de tornar o município de Três Lagoas o maior produtor mundial de celulose de fibra curta.

Nesse contexto, para Dantas (2016), o conceito de lugar é importante para a análise de fenômenos econômicos quando se utiliza a teoria dos circuitos espaciais de produção. Isso porque, apesar da mobilidade, em função da circulação e da comunicação, os circuitos necessitam de uma base material. A circulação e a comunicação são duas características da mobilidade existente nos circuitos. São elas que viabilizam os fluxos materiais e imateriais. Estes fluxos são sustentados por uma base material, evidenciando a importância da configuração territorial e da singularidade dos lugares. Em decorrência disso, o conceito de lugar é fundamental nas pesquisas relacionadas aos circuitos espaciais de produção.

Como citado anteriormente, defende-se a ideia de que a estruturação e a expansão do circuito espacial produtivo de celulose em Mato Grosso do Sul, sobretudo em sua região Leste, foram possibilitadas devido à combinação de oito fatores. Foram esses fatores, essas especificidades, que atraíram os agentes hegemônicos do circuito espacial produtivo de celulose para o estado de Mato Grosso do Sul, evidenciando a importância do lugar, conforme será evidenciado no próximo item.

\section{Os oito fatores fundamentais para a estruturação e a expansão do circuito espacial produtivo em Mato Grosso do Sul}

Os fatores viabilizadores da estruturação e da expansão do circuito espacial produtivo de celulose em Mato Grosso do Sul, conforme apresentado anteriormente, são: baixa densidade técnica das atividades agropecuárias pré-existentes; disponibilidade de terras de menor preço; concentração fundiária; mão de obra barata; pré-existência de uma base florestal; localização geográfica; disponibilidade hídrica; e, atuação do Estado.

Do ponto de vista agropecuário, o Leste divergia de outras regiões de Mato Grosso do Sul, precipuamente no que diz respeito à densidade técnica das atividades desenvolvidas. Até meados da década de 2000, a principal atividade agropecuária desenvolvida na região era a pecuária extensiva. Enquanto isso, outras regiões de MS - Sul e no Norte do estado - estavam 
ocupadas há décadas por atividades agropecuárias modernas ${ }^{4}$ do ponto de vista técnico, como a soja, o milho e a cana-de-açúcar.

Vale salientar que o Mato Grosso do Sul, na década de 2000, possuía outra região ainda não ocupada pela agricultura moderna: o Oeste do estado. No entanto, sua expansão não seria tão viável como no Leste, sobretudo por boa parte estar no domínio morfoclimático do Pantanal. Possivelmente, o circuito espacial produtivo de celulose, assim como qualquer atividade agropecuária moderna, enfrentaria grandes entraves para sua expansão no Pantanal, principalmente por parte do poder público, das organizações não governamentais (ONG's) e dos ativistas ambientais, o que não ocorreu no Leste do estado, onde sua expansão ocorreu sem maiores dificuldades. Nos últimos anos, entretanto, a expansão das atividades agropecuárias modernas, principalmente a soja e o milho, também tem ocorrido no Pantanal.

Extrapolando a divisa de Mato Grosso do Sul, outras frações do território próximas localizadas em outras unidades da federação também estavam ocupadas pela agricultura moderna na década de 2000. O Oeste do estado de São Paulo, por exemplo, estava ocupado pela monocultura canavieira, enquanto o Sul de Mato Grosso e de Goiás estavam ocupados pelos monocultivos de grãos, principalmente soja e milho.

Deste modo, como quase todas as frações de território próximas estavam ocupadas por atividades agropecuárias modernas, como o Oeste de Mato Grosso do Sul possuía o Pantanal como entrave para a expansão da agricultura moderna, o Leste apresentava-se como uma das frações do Centro-Sul do Brasil disponível para a expansão de uma atividade moderna na década de 2000.

A inexistência de atividade agropecuária moderna contribuiu para a estruturação e a expansão do circuito espacial produtivo de celulose em MS, haja vista que, para a produção de celulose, seria necessária grande quantidade de terras para o plantio do monocultivo de eucalipto, matéria-prima utilizada na produção da celulose produzida no estado. A existência de atividade agropecuária moderna poderia dificultar a expansão do circuito espacial produtivo de celulose, pois a disputa pelo território seria mais intensa.

Cita-se como exemplo o Sudoeste de Goiás, onde fazendeiros produtores de grãos, principalmente soja e milho, uniram-se com o intuito de frear a expansão da cana-de-açúcar. Em Jataí e Rio Verde, por exemplo, leis foram criadas para limitar a área ocupada pela canade-açúcar (O POPULAR, 21/01/2011). Nesse sentido, a expansão do cultivo de eucalipto em áreas de agricultura moderna poderia ocasionar situação similar.

A concorrência por terras entre diferentes agentes da agricultura moderna revela uma disputa distinta da disputa desigual entre o agronegócio e o campesinato, onde, em razão de seu poder econômico e político, o agronegócio se coloca com supremacia. No caso da disputa entre os agentes da monocultura canavieira e os agentes das monoculturas de grãos, a disputa é mais igualitária, principalmente do ponto de vista econômico. A diferença que pesa em favor dos fazendeiros produtores de grãos é o fato de estarem a mais tempo no Sudoeste de Goiás, dotando-os de maior poder político. Assim, apesar do poderio econômico de seus agentes, a monocultura canavieira encontrou limitações para sua expansão nesta fração do território goiano em razão do poderio político dos fazendeiros produtores de grãos.

A inexistência de uma atividade agropecuária moderna no Leste sul-mato-grossense ocasionou outro fator extremamente importante para a estruturação e expansão do circuito espacial produtivo de celulose: o menor preço das terras. Até meados da década de 2000, o preço das terras no Leste sul-mato-grossense era inferior se comparado ao preço das terras próximas onde a agricultura moderna já havia se territorializado, como no Sul e Norte de

${ }^{4}$ É importante destacar que, nesta pesquisa, quando se fala em atividades agropecuárias modernas, faz-se referência ao seu aspecto técnico. 
Mato Grosso do Sul, Oeste do estado de São Paulo e no Sul dos estados do Mato Grosso e de Goiás.

Além da inexistência de atividades agropecuárias modernas, o menor preço das terras no Leste sul-mato-grossense também era ocasionado pelas

[...] características específicas dos solos predominantes (Latossolo Vermelho Distrófico, Argissolo Vermelho Amarelo, Neossolo Quartzarenico), que, segundo o Estudo que deu base ao Zoneamento Ecológico-Econômico de Mato Grosso do Sul (ZEE-MS, 2009), têm baixa aptidão agrícola e grande suscetibilidade à erosão, e ainda, o longo processo de degradação pela atividade pecuária que se fez hegemônica desde a chegada dos primeiros “colonizadores", no início do século XX (PERPETUA, 2012, p. 155).

Segundo Aires Galhardo, diretor florestal da Fibria, a diferença no preço da terra pode deixar um projeto de implantação de uma fábrica produtora de celulose até $\mathrm{R} \$ 700$ milhões (Setecentos milhões de reais) mais caro. Conforme o diretor, em Mato Grosso do Sul, a instalação de uma unidade industrial com capacidade para produzir 1,5 milhão de toneladas de celulose por ano custaria por volta de R $\$ 1,8$ bilhão, enquanto em São Paulo seriam necessários cerca de R $\$ 2,5$ bilhões (FOLHA, 20/10/2011).

Como qualquer atividade agroindustrial, a planta industrial produtora de celulose necessita localizar-se o mais próximo possível da matéria-prima. As grandes distâncias inviabilizam financeiramente algumas atividades agroindustriais em decorrência dos custos elevados com o transporte da matéria-prima.

A disponibilidade de terras com preços menores no Leste sul-mato-grossense possibilitou maior controle territorial por parte das companhias, aproximando o monocultivo de eucalipto das unidades industriais e, consequentemente, reduzindo os custos com o frete que, segundo Biazus, Hora e Leite (2010), se constitui como o segundo maior custo da produção de celulose de fibra curta, representando $16 \%$ do total, atrás apenas dos custos com madeira $(41 \%)$.

Na unidade da Fibria em Três Lagoas, por exemplo, a distância média entre a base florestal e a planta industrial é de 94 quilômetros. Enquanto isso, em Aracruz, no Espírito Santo, a distância média entre a fábrica e a base florestal é de 233 quilômetros (Tabela 1).

Tabela 1. Fibria: distância média entre a base florestal e as unidades industriais

Fonte: FIBRIA, 2015.

\begin{tabular}{lc}
\hline Unidade & Quilômetros (km) \\
\hline Aracruz & 233 \\
Jacareí & 232 \\
Três Lagoas & 94 \\
\hline
\end{tabular}

Vale salientar que a realidade dos preços menores das terras do Leste sul-matogrossense não existe mais. A partir da expansão do circuito espacial produtivo de celulose, as terras do Leste de Mato Grosso do Sul tiveram seus preços majorados. No momento atual, o preço das terras na referida região é muito próximo, podendo até superar o preço das terras das regiões citadas anteriormente (Sul e Norte de Mato Grosso do Sul, Sul de Goiás e Mato Grosso e Oeste de São Paulo).

O aumento do preço das terras tem provocado diversos impactos, como, por exemplo, a inviabilização da reforma agrária (KUDLAVICZ, 2011; NARDOQUE e ALMEIDA, 2015). Os próprios agentes do circuito espacial produtivo de celulose foram afetados pelo aumento 
do preço das terras nos últimos anos. Segundo Kudlavicz (2011, p. 155), em determinado momento, as empresas produtoras de celulose estipularam um preço máximo pelo alqueire paulista $^{5}$ a ser pago pelas terras.

A região do Distrito de Arapuá, distante 50 quilômetros da cidade, sofre uma valorização maior devido à procura de terras para uso como chácaras de lazer, cujo valor do alqueire tem sido negociado entre 20 e 25 mil reais, dependendo das benfeitorias existentes. A especulação ganhou ritmo tão acelerado que houve necessidade de intervenção no mercado de terras por parte das papeleiras. Segundo o proprietário da referida imobiliária: —as empresas compradoras de eucalipto limitaram o valor da compra de terras para áreas acima de 50 quilômetros distantes da sede do município, para viabilizar economicamente o projeto de reflorestamento, no valor máximo de 8 mil a 10 mil o alqueire paulista. (KUDLAVICZ, 2011, p.155).

A elevada concentração fundiária existente no Leste sul-mato-grossense foi outro fator facilitador da expansão do circuito espacial produtivo de celulose, tendo em conta que, como mencionado anteriormente, esse circuito necessita de base territorial para a expansão da produção de eucalipto, realizada em médias e grandes extensões de terra. Deste modo, sua expansão foi facilitada em razão da concentração fundiária, característica histórica de Mato Grosso do Sul (ALMEIDA, 2010; KUDLAVICZ, 2011; PERPETUA, 2012; NARDOQUE, 2016).

A Tabela 2 evidencia a estrutura fundiária do Leste sul-mato-grossense ainda mais concentrada em comparação à estadual. Percentualmente, tanto o número como a área ocupada pelos estabelecimentos de até 200 hectares é menor no Leste se comparado ao estado de Mato Grosso do Sul. Enquanto no estado os estabelecimentos de até 200 hectares representam $72,4 \%$ do número total de estabelecimentos e ocupam $5 \%$ da área, no Leste os estabelecimentos de até 200 hectares representam 60,1\% do total e ocupam 4,53\% da área.

Nesse contexto, os estratos de propriedades entre 200 e 1.000 hectares e com mais de 1.000 hectares são, percentualmente, mais numerosas e ocupam maior área no Leste sul-matogrossense. Juntos, esses dois grupos de áreas, apresentados na Tabela 2, representam 39,9\% do total de estabelecimentos e ocupam $95,47 \%$ da área dos estabelecimentos, enquanto no total do estado esses dois grupos de área retratam $27,6 \%$ do total de estabelecimentos e controlam $95 \%$ da área dos estabelecimentos de Mato Grosso do Sul.

Tabela 2. Mato Grosso do Sul e Leste do estado: número e área dos estabelecimentos agropecuários

\begin{tabular}{lcccccccc}
\hline & \multicolumn{3}{c}{ Mato Grosso do Sul } & \multicolumn{3}{c}{ Leste de Mato Grosso do Sul } \\
\hline & Número & $\%$ & Área & $\%$ & Número & $\%$ & Área & $\%$ \\
Até 200 ha & 46.728 & 72,4 & 1.501 .220 & 5,0 & 8.543 & 60,1 & 377.899 & 4,53 \\
$\begin{array}{l}\text { Entre 200 e } \\
1.000 \text { ha }\end{array}$ & 11.175 & 17,3 & 5.428 .648 & 17,9 & 3.611 & 25,4 & 1.821 .345 & 21,85 \\
$\begin{array}{l}\text { Mais de } \\
\begin{array}{l}1.000 \text { ha } \\
\text { Total }\end{array}\end{array}$ & 6.661 & 10,3 & 23.345 .109 & 77,1 & 2.052 & 14,5 & 6.137 .995 & 73,62 \\
& 64.564 & 100 & 30.274 .977 & 100 & 14.206 & 100 & 8.337 .239 & 100 \\
\hline
\end{tabular}

Fonte: IBGE, 2006.

A estrutura fundiária concentrada facilita a aquisição ou arrendamento de terras, pois o número de negociações é menor. Em uma região onde a concentração fundiária é menor, o fracionamento da terra é maior, resultando em um número maior de propriedades.

\footnotetext{
${ }^{5} \mathrm{O}$ alqueire paulista equivale a $24.200 \mathrm{~m}^{2}$.
} 
Consequentemente, o número de negociações será maior, aumentando as possibilidades de insucesso por parte dos agentes que buscam comprar ou arrendar terras.

Como necessita de grandes extensões de terras, o circuito espacial produtivo de celulose encontrou na estrutura fundiária concentrada de Mato Grosso do Sul, mais precisamente da região Leste, as condições ideais para sua expansão. Nesse sentido, para Perpetua (2016), a estratégia do circuito espacial produtivo de celulose é extremamente territorial, no sentido de controle do território.

Atrelado à estrutura fundiária, outra característica que merece destaque é o forte absenteísmo presente no Leste de Mato Grosso do Sul. Segundo Nardoque (2016), em Três Lagoas, por exemplo, cerca de $80 \%$ dos proprietários de terras não residem no município, sendo que quase $70 \%$ residem em outras unidades da federação, como São Paulo, demonstrando o caráter rentista da propriedade da terra, além da reduzida relação dos proprietários com suas terras. Características que também favoreceram a expansão do circuito espacial produtivo de celulose em MS.

Esse contexto evidencia que, apesar de o circuito espacial produtivo de celulose ser moderno do ponto de vista técnico, sua estruturação e expansão foram viabilizadas, dentre outros fatores, por características tradicionais presentes no campo brasileiro, como a concentração fundiária e o caráter rentista da terra. Tal conjuntura revela a ocorrência de uma combinação perversa entre o "moderno" e o "arcaico", fundamental para a expansão do capitalismo (OLIVEIRA, 2003).

A concentração fundiária somada ao absenteísmo e ao preço baixo das terras, quando comparado com o preço de outras regiões próximas, possibilitou as companhias maior controle territorial no Leste de Mato Grosso do Sul, por meio da compra ou do arrendamento de terras. Nos municípios onde a terra é mais cara e a estrutura fundiária é menos concentrada, as companhias não conseguem o mesmo controle do território como o verificado em Mato Grosso do Sul. Tal situação resulta, por exemplo, na necessidade de quantidade maior de contratos de fomento florestal.

Em Aracruz (ES), por exemplo, a Fibria possuía, em 2015, 1.853 contratos de fomento florestal, enquanto em Três Lagoas existiam apenas dois (Tabela 3). Essa situação revela que, em Três Lagoas, em virtude da concentração fundiária e do preço menor das terras, a companhia conseguiu comprar e/ou arrendar quantidade de terras suficiente para sua base florestal, atingindo quase a autossuficiência. Em Aracruz, por sua vez, isso não foi possível, tornando o fomento florestal uma prática recorrente.

Tabela 3.Fibria: fomento florestal: número de contratos, percentual de abastecimento e área contratada (2015)

\begin{tabular}{lccc}
\hline Unidade & $\mathbf{N}^{\mathbf{0}}$ de contratos & \% do abastecimento & Área contratada (ha) \\
\hline Aracruz (ES) & 1.853 & 36,7 & 45.800 \\
Jacareí (SP) & 127 & 11,9 & 8.029 \\
Três Lagoas (MS) & 2 & 0,9 & 1.813 \\
\hline
\end{tabular}

Fonte: FIBRIA, 2015.

A concentração fundiária elevada do Leste sul-mato-grossense tem um reflexo intrínseco: a pequena presença do campesinato e, por conseguinte, dos movimentos sociais rurais. Uma estrutura fundiária menos concentrada possui número maior de propriedades controladas por camponeses. Os camponeses, por sua vez, organizados em movimentos sociais, podem se constituir como empecilho para a expansão dos monocultivos florestais. Segundo Perpetua (2012), as atividades florestais no Brasil têm sido transferidas das áreas tradicionais para novas áreas, como o Leste de MS, dentre outros fatores, em decorrência dos 
conflitos com movimentos sociais ligados aos camponeses ou as comunidades tradicionais (quilombolas, indígenas, extrativistas), evidenciando o poder de pressão dos sujeitos sociais.

Se a expansão do agronegócio pode ser dificultada em determinadas frações do território, onde a concentração fundiária é menor e a presença dos movimentos sociais é maior, no Leste de Mato Grosso do Sul, em função da elevada concentração fundiária e da pequena presença dos movimentos sociais, as dificuldades para a estruturação e expansão do circuito espacial produtivo de celulose praticamente inexistiram. Em poucos anos, sem maiores dificuldades, os agentes do circuito espacial produtivo de celulose conseguiram formar a base territorial necessária para a expansão do monocultivo de eucalipto, visando o abastecimento das unidades fabris produtoras de celulose.

Entende-se que a mão de obra barata é mais um fator importante para a estruturação e a consequente expansão do circuito espacial produtivo de celulose em Mato Grosso do Sul. Conforme dados presentes no Cadastro Geral de Empregados e Desempregados (CAGED) (Tabela 4), os trabalhadores empregados nas indústrias de transformação no município de Três Lagoas, sede das duas fábricas de celulose do estado, possuem uma das menores médias salariais entre municípios que possuem fábricas de celulose de mercado e/ou integradas ${ }^{6}$. Nesse aspecto, os trabalhadores de Três Lagoas encontram-se a frente apenas dos municípios de Belo Oriente (MG), Eunápolis (BA) e Imperatriz (MA).

Tabela 4. Brasil: médias salariais dos trabalhadores nas indústrias de transformação em municípios selecionados (2010 e 2016)

\begin{tabular}{lcc}
\hline Município & $\mathbf{2 0 1 0}$ & $\mathbf{2 0 1 6}$ \\
\hline Mucuri (BA) & $1.678,73$ & $3.056,35$ \\
Luis Antônio (SP) & $1.351,22$ & $2.788,90$ \\
Jacareí (SP) & $1.450,74$ & $2.632,29$ \\
Ortigueira (PR) & 903,75 & $2.487,62$ \\
Mogi Guaçu (SP) & $1.304,91$ & $2.285,31$ \\
Guaíba (RS) & $1.359,37$ & $2.249,90$ \\
Aracruz (ES) & $1.344,42$ & $2.190,88$ \\
Três Lagoas (MS) & 714,57 & $1.600,69$ \\
Belo Oriente (MG) & $1.153,54$ & $1.587,05$ \\
Eunápolis (BA) & $1.049,39$ & $1.532,97$ \\
Imperatriz (MA) & 626,11 & $1.430,20$ \\
\hline
\end{tabular}

Fonte: MTE/CAGED, 2017.

Levando em consideração apenas municípios que a Fibria possui unidades fabris, Três Lagoas ocupa a última colocação, tendo em vista que Jacareí e Aracruz possuem médias salariais bem superiores em relação ao município sul-mato-grossense. Tal situação evidencia que, do ponto de vista do custo com a mão de obra industrial, Três Lagoas apresenta-se mais vantajosa.

Situação similar pode ser verificada quando são analisados os dados referentes às médias salariais dos trabalhadores empregados na fabricação de celulose, papel e produtos de papel (Tabela 5). Nesta variável, Três Lagoas encontra-se a frente apenas dos municípios de Eunápolis e Ortigueira. No que diz respeito apenas aos municípios onde a Fibria possui unidades fabris, Três Lagoas permanece ocupando a menor média salarial.

\footnotetext{
${ }^{6}$ Foram selecionados municípios que possuem fábricas de celulose de mercado e/ou integrada antigas e/ou inauguradas recentemente.
} 
Tabela 5. Brasil: médias salariais dos trabalhadores na fabricação de celulose, papel e produtos de papel em municípios selecionados (2010 e 2016)

\begin{tabular}{lcc}
\hline \multicolumn{1}{c}{ Município } & $\mathbf{2 0 1 0}$ & $\mathbf{2 0 1 6}$ \\
\hline Jacareí (SP) & $3.801,04$ & $5.386,49$ \\
Imperatriz (MA)* & - & $4.608,59$ \\
Mucuri (BA) & $3.236,68$ & $4.453,42$ \\
Luis Antônio (SP) & $2.735,45$ & $3.930,82$ \\
Belo Oriente (MG) & $2.557,72$ & $3.831,17$ \\
Guaíba (RS) & $2.044,43$ & $3.404,08$ \\
Aracruz (ES) & $4.113,32$ & $3.326,86$ \\
Mogi Guaçu (SP) & $2.991,80$ & $3.306,17$ \\
Três Lagoas (MS) & $1.863,83$ & $3.083,00$ \\
Eunápolis (BA) & $1.962,76$ & $2.999,24$ \\
Ortigueira (PR)* & - & $2.956,82$ \\
\hline
\end{tabular}

*Em 2010 ainda não existiam fábricas de celulose.

Fonte: MTE/CAGED, 2017.

Os dados apresentados nas tabelas 4 e 5 evidenciam que a mão de obra barata pode ser considerada um fator importante para atrair as companhias produtoras de celulose, sobretudo a Fibria, para o Mato Grosso do Sul, especialmente para Três Lagoas. Esses dados, todavia, revelam mais uma característica importante para a estruturação e a expansão do circuito espacial produtivo de celulose: a incipiente organização sindical.

Como mencionado anteriormente, o Mato Grosso do Sul, em menos de uma década, tornou-se um dos principais produtores de celulose do Brasil. Entretanto, apesar do crescimento produtivo deste segmento, a média salarial continua baixa, quando comparada a municípios de outras unidades da federação, revelando o reduzido poder de pressão por parte dos sindicatos localizados no estado.

Segundo o presidente do Sindicato dos Trabalhadores Florestais (SINTRAF), nas regiões onde as fábricas de celulose estão há mais tempo, os sindicatos são mais organizados e conseguem resultados mais expressivos, como, por exemplo, melhores salários e condições de trabalho. Para o entrevistado, nesse sentido, em Três Lagoas a organização sindical existente no setor é muito fraca e isso impossibilita ganhos significativos para os trabalhadores e, por consequência, favorece as empresas produtoras de celulose. Ademais, o entrevistado também informou que as empresas de celulose incentivam seus trabalhadores a não possuírem relações com sindicatos, dificultando, por consequência, a atuação destes.

O quinto fator viabilizador da estruturação e da expansão do circuito espacial produtivo de celulose no Leste de Mato Grosso do Sul foi a existência de uma base florestal pré-existente, pois durante a década de 1970, devido aoPrograma de Desenvolvimento dos Cerrados (POLOCENTRO), que integrava o II Plano Nacional de Desenvolvimento (PND) (1975-1979), foram implantadas áreas de cultivo de eucalipto e pinus entre os municípios de Campo Grande e Três Lagoas (KUDLAVICZ, 2011), para a produção de carvão e madeira.

Além da importância do II PND e do POLOCENTRO, os primeiros monocultivos florestais, na área entre Campo Grande e Três Lagoas, também foram incentivados pela Lei 5.106, de 02 de setembro de 1966, que visava conceder incentivos fiscais a empreendimentos florestais. Somados aos incentivos fiscais, o Estado também financiou, naquele período, por meio do Banco Nacional de Desenvolvimento Econômico e Social (BNDES), a expansão dos monocultivos florestais em MS (KUDLAVICZ, 2011; PERPETUA, 2012).

A partir da atuação do Estado, no decorrer da década de 1970, os monocultivos florestais se expandiram na área mencionada. No início da década de 1980, no entanto, em decorrência do fim dos incentivos fiscais, os monocultivos florestais foram significativamente reduzidos. Boa parte dos investidores abandonaram seus empreendimentos florestais, que passaram a ser tomados pelas pragas ou queimados. Parte do que "[...] escapou ao ataque de 
pragas e à ação do fogo, foi entregue à produção de carvão no início dos anos de 1990, para ser consumido nos fornos das siderúrgicas de Minas Gerais e São Paulo" (KUDLAVICZ, 2011, p. 48-49).

Apesar da redução de investimentos e da área plantada, entre as décadas de $1980 \mathrm{e}$ 1990 e início da década de 2000, os monocultivos florestais continuaram a existir na área entre Campo Grande e Três Lagoas, abastecendo, mormente, carvoarias e serrarias (KUDLAVICZ, 2011).

Mesmo em quantidade reduzida, a base florestal pré-existente contribuiu para o início das atividades industriais da primeira fábrica produtora de celulose instalada no município de Três Lagoas. Evidente que essa base florestal pré-existente não foi suficiente para atender a demanda da fábrica, pois, como esta nasceu como uma das maiores fábricas produtoras de celulose do mundo, a demanda era grande e as áreas plantadas com eucalipto existentes no Leste de Mato Grosso do Sul não eram suficientes. Destarte, parte das toras de eucalipto era originária de outras unidades da federação.

A localização geográfica de Mato Grosso do Sul, sobretudo da região Leste, é outro fator que merece destaque e foi essencial para a estruturação e a expansão do circuito espacial produtivo de celulose. O Leste de MS está localizado no centro da América do Sul, facilitando o acesso aos países do Mercado Comum do Sul (MERCOSUL) (PERPETUA, 2012). Do ponto de vista interno, o Leste sul-mato-grossense está próximo aos principais mercados consumidores do Brasil, como o Sul e, principalmente, o Sudeste. Além disso, soma-se a proximidade com o Porto de Santos, facilitada pela possibilidade de uso de diferentes modais.

A localização geográfica do Leste de Mato Grosso do Sul pouco adiantaria se não existissem infraestruturas para viabilizar a integração desta fração do território com outros estados brasileiros e países. Nessa perspectiva, pode-se dizer que as infraestruturas criadas potencializam a localização geográfica.

Para Santos (2006), a infraestrutura é um dos elementos de ordem técnica que possibilita maior ou menor rentabilidade aos investimentos em determinado lugar. Assim, quanto melhor a infraestrutura de uma fração do território ou de um lugar, maior sua possibilidade de oferecer rentabilidade às empresas ali instaladas.

Ainda segundo o autor supracitado, a infraestrutura é criada, principalmente, "[...] para atender as necessidades geográficas das empresas [...]" (SANTOS, 2006, p. 229). Nesse sentido, para se instalarem no Leste de Mato Grosso do Sul, as empresas tiveram como contrapartida do Estado, nas instâncias federal, estadual e municipal, a garantia da criação de infraestrutura ou da melhoria da infraestrutura existente, como, por exemplo, as obras que melhoraram as condições da BR-158 no trecho entre Três Lagoas e Brasilândia, onde está localizada a Fibria.

Durante décadas o referido trecho ficou abandonado pelo poder público, situação que causava transtorno aos motoristas, por conta de suas péssimas condições. No entanto, a partir da instalação da Fibria, tal situação foi alterada e a rodovia passou por ampla reforma, além de receber reparos frequentes, evidenciando que os investimentos em infraestrutura são realizados para beneficiar, sobretudo, as empresas.

É por meio da infraestrutura criada, ou seja, dos objetos fixos, que as empresas produtoras de celulose recebem, por exemplo, fluxos de insumos e equipamentos originários de outros estados brasileiros e de outros países, mas também emitem fluxos de mercadorias a seus clientes localizados em mais de 40 países do mundo.

Em decorrência das infraestruturas criadas, as unidades industriais produtoras de celulose do Leste sul-mato-grossense têm a possibilidade de utilizar modais distintos, como o rodoviário, o ferroviário, o hidroviário e o aeroviário, facilitando a integração com outros estados brasileiros e países. 
A integração rodoviária do Leste sul-mato-grossense ocorre, precipuamente, por meio das rodovias BR-262, BR-158 e SP-300. A BR-262 corta o Mato Grosso do Sul de Leste a Oeste, ligando-o a Bolívia, no Oeste, e ao estado de São Paulo, no Leste, em um trajeto de aproximadamente 800 quilômetros. A BR-262 também liga o Leste a Campo Grande, capital do estado, distante cerca de 320 quilômetros de Três Lagoas, sede das fábricas produtoras de celulose. Atravessando o rio Paraná, a BR-262 transforma-se em SP-300, ligando o Leste de Mato Grosso do Sul ao Oeste do estado de São Paulo. A BR-158 liga o Leste de MS ao Sul do estado e ao Sul de Goiás. É nesta rodovia, inclusive, que estão localizadas as plantas agroindustriais produtoras de celulose. A Fibria está no sentido ao Sul, a cerca de 35 quilômetros da cidade de Três Lagoas, enquanto a Eldorado está em direção ao Norte, a aproximadamente 42 quilômetros da referida cidade.

O modal ferroviário é utilizado pelas empresas do circuito espacial produtivo para o escoamento da produção de celulose. As ferrovias utilizadas são a ALL Malha Norte S.A., a ALL Malha Oeste S. A. e a ALL Malha Paulista S.A., todas operadas pela América Latina Logística S.A. (ALL) ${ }^{7}$.

O transporte da celulose produzida pelas fábricas inicia-se nas malhas Oeste e Norte, mas, a partir dos municípios de Bauru e Santa Fé do Sul, a celulose é transportada sob os trilhos da Malha Paulista (antiga Ferroban) até o Porto de Santos, localizado no litoral paulista.

O modal hidroviário é outra possibilidade para o escoamento da celulose produzida em Mato Grosso do Sul. Apesar de as duas fábricas de celulose estarem localizadas às margens do rio Paraná, apenas a Eldorado Brasil utilizou o modal hidroviário para o escoamento da produção no ano de 2016. A companhia utiliza, sobretudo, a parte da hidrovia Tietê-Paraná localizada no estado de São Paulo, até o Terminal Intermodal de Anhembi.

O modal aeroviário foi o último da ser implantado no Leste de Mato Grosso do Sul. O Aeroporto Regional "Plínio Alarcon" (TJL), localizado em Três Lagoas, foi homologado pela Agência Nacional de Aviação Civil (ANAC) no ano de 2013. Apesar do desejo antigo da população e das lideranças regionais, a mobilização para a construção do aeroporto com o intuito de integrar o Leste de Mato Grosso do Sul a malha aeroviária brasileira teve início, de fato, no final da década de 2000, em função, especialmente, da expansão do circuito espacial produtivo de celulose. As obras para a construção do aeroporto custaram cerca de R\$ 4.200.000,00 (Quatro milhões e duzentos mil reais), contando com recursos dos governos federal, estadual e municipal (TRÊS LAGOAS, 2013). Em 2019, apenas a Azul Linhas Aéreas opera na cidade com uma linha com destino a Campinas (VCP) (SP).

O Mapa 1 evidencia a localização das plantas industriais da Fibria e da Eldorado Brasil em Três Lagoas, às margens do rio Paraná, na divisa com o estado de São Paulo, bem como a infraestrutura existente no Leste do MS e no estado vizinho. Tal situação evidencia que a localização das fábricas produtoras de celulose é estratégica, pois utilizam a infraestrutura do Leste do MS e do estado vizinho, São Paulo.

\footnotetext{
${ }^{7}$ Em abril de 2015, a ALL foi absorvida pela Rumo Logística, empresa do Grupo Cosan, em um processo de fusão entre as duas empresas.
} 
Mapa 1. Leste de Mato Grosso do Sul e São Paulo: localização da Fibria, da Eldorado e a infraestrutura

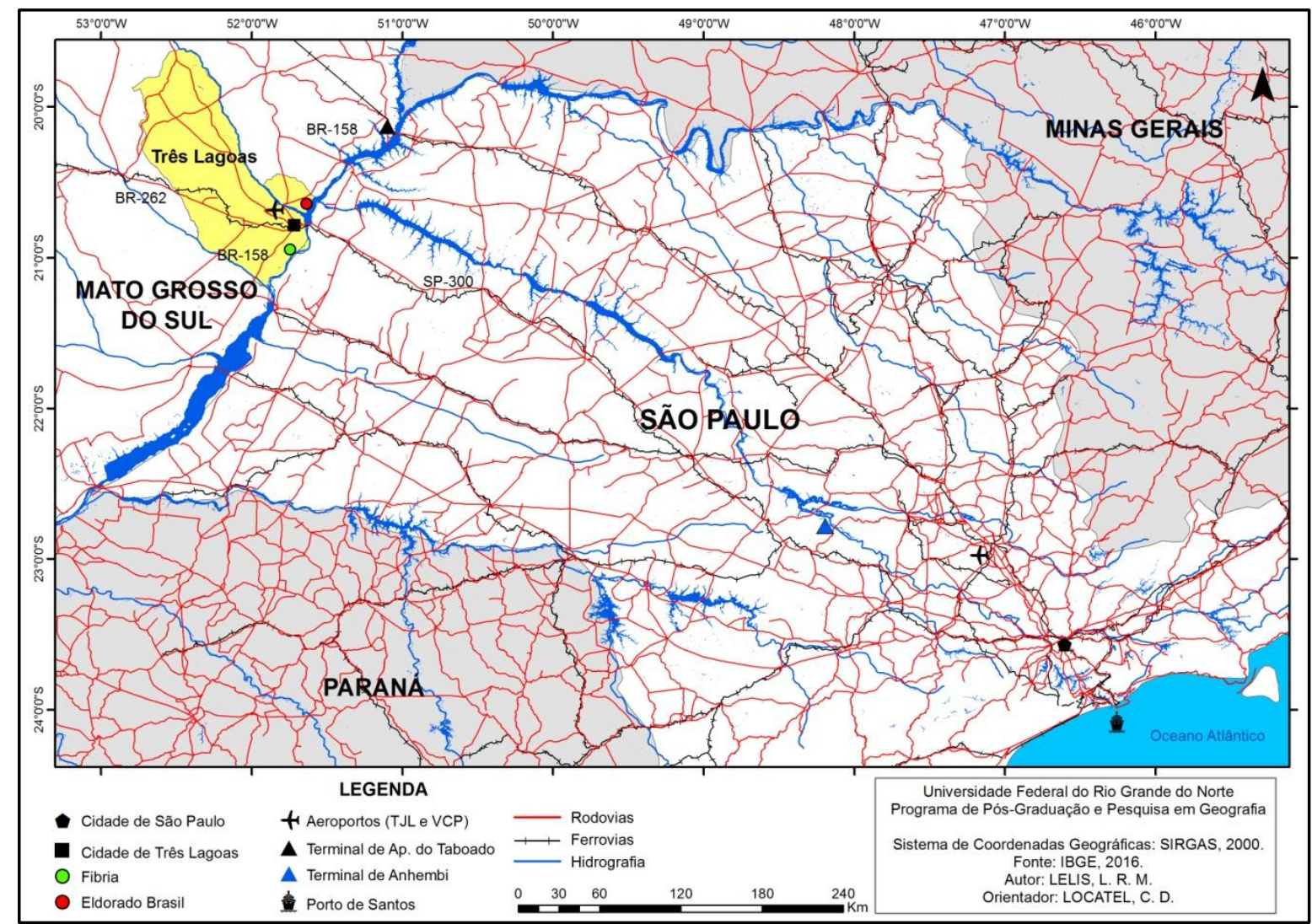

Fonte: IBGE, 2016.

Como mencionado, a localização das duas fábricas de celulose às margens do rio Paraná possibilita a utilização do modal hidroviário. Entretanto, a localização estratégica das unidades fabris não visa apenas à possibilidade do transporte hidroviário, pois existe um objetivo ainda maior: garantir o acesso aos recursos hídricos. Este se configura como mais um fator importante para a estruturação e expansão do circuito espacial produtivo de celulose em Mato Grosso do Sul.

Além do rio Paraná, o Leste sul-mato-grossense possui outros rios importantes, afluentes, como os rios Pardo, Verde e Sucuriú. Tal característica evidencia a disponibilidade hídrica existente na região Leste.

Os pesquisadores defensores das atividades florestais afirmam, por meio de suas pesquisas, que o eucalipto consome a mesma quantidade de água que qualquer outra árvore. No entanto, a população do campo afirma que o nível dos cursos d'água passou a diminuir em diversos lugares do território brasileiro em razão da expansão do monocultivo de eucalipto, conforme demonstra Perpetua (2016), evidenciando, de certo modo, a divergência entre os saberes científico e tradicional.

Mesmo que o eucalipto consuma a mesma quantidade de água que qualquer outra árvore, existem duas questões que devem ser levadas em consideração: os poucos estudos existentes sobre a relação entre a água e o monocultivo de eucalipto no Cerrado; e, a grande área ocupada pelo eucalipto em Mato Grosso do Sul (PERPETUA, 2016), pois os eucaliptais ocupavam, em 2016, cerca de 900 mil de hectares no estado, estando concentrados, sobretudo, na região Leste. Somente a Fibria e a Eldorado possuíam juntas 515 mil hectares plantados com eucalipto. 
Saindo do debate sobre o consumo de água pelo eucalipto, o fato é que a água é vital para qualquer tipo de agronegócio. Segundo Thomaz Junior (2010), o acesso à água é fundamental para o sucesso do empreendimento agropecuário. Para o autor, existe um "Polígono do Agrohidronegócio" formado pelo Noroeste do Paraná, Oeste do estado de São Paulo, Leste de Mato Grosso do Sul, Triângulo Mineiro e Sul e Sudoeste de Goiás. De acordo com Thomaz Junior (2010), dentre outras características, a disponibilidade hídrica, superficial e subterrânea, possui destaque nesse polígono.

A água não é importante apenas para o crescimento dos eucaliptos, mas também para as operações industriais. Durante a produção industrial da celulose a água é utilizada em diversas etapas do processo produtivo, conforme será evidenciado no decorrer da pesquisa. Toda a água utilizada nas operações industriais das fábricas é captada diretamente no rio Paraná.

Segundo a Fibria, em 2015, as operações de manejo florestal das suas três unidades industriais (Aracruz, Jacareí e Três Lagoas) consumiram 362.256 metros cúbicos $\left(\mathrm{m}^{3}\right)$ de água $^{8}$, enquanto as operações industriais necessitaram de $36.254 .494 \mathrm{~m}^{3}$ de água, evidenciando sua importância, principalmente para suas atividades industriais.

A Eldorado Brasil também não fica atrás, pois utiliza grande quantidade de água para suas operações. Em 2016, por exemplo, a companhia consumiu $43.532 .160,35 \mathrm{~m}^{3} \mathrm{de}$ água(Tabela 6).

Tabela 6. Eldorado Brasil: consumo de água por fonte (2013-2016)

\begin{tabular}{lcccc}
\hline $\begin{array}{l}\text { Água retirada } \\
\text { (por fonte) }\end{array}$ & $\mathbf{2 0 1 3}$ & $\mathbf{2 0 1 4}$ & $\mathbf{2 0 1 5}$ & $\mathbf{2 0 1 6}$ \\
\hline Água superficial $\left(\mathrm{m}^{3}\right)$ & $39.478 .754,00$ & $46.588 .677,00$ & $45.611 .125,14$ & $43.181 .518,35$ \\
Água subterrânea $\left(\mathrm{m}^{3}\right)^{*}$ & $475.498,00$ & $451.263,00$ & $348.817,00$ & $350.642,00$ \\
Total & $39.964 .252,00$ & $47.039 .940,00$ & $45.959 .942,14$ & $43.532 .160,35$ \\
\hline
\end{tabular}

* Referente ao consumo de água do viveiro localizado em Andradina - SP.

Fonte: ELDORADO BRASIL, 2016.

Destarte, apesar de as companhias afirmarem que mais de $90 \%$ da água captada para as operações industriais é devolvida ao rio após tratamento, fica evidente que suas localizações às margens do rio Paraná são extremamente estratégicas, visando garantir o acesso à água.

A atuação irrestrita do Estado é o último e mais importante fator para a estruturação e a expansão do circuito espacial produtivo de celulose em Mato Grosso do Sul. O apoio do Estado ao circuito estudado ocorreu nas instâncias federal, estadual e municipal e envolveu financiamentos, incentivos fiscais, instalação ou melhoramento da infraestrutura e flexibilização da legislação ambiental.

O Estado, na instância federal, atuou, principalmente, na concessão de financiamentos às empresas do circuito espacial produtivo de celulose, pois, a partir da elaboração de políticas públicas, como a Política Industrial, Tecnológica e de Comércio Exterior (PITCE), lançada em 2004, a Política de Desenvolvimento Produtivo (PDP), lançada em 2008, que substituiu a PITCE, ambas no Governo Lula, e o Plano Brasil Maior (PBM), no primeiro mandato de Dilma Rousseff (2011-2014). Conforme Silva (2016, p. 98), essas três políticas, "[...] cada uma na sua intensidade, inseriram a indústria brasileira no mercado internacional".

\footnotetext{
${ }^{8}$ Vale salientar que esse consumo de água está relacionado ao consumo registrado. As atividades florestais, certamente, consomem quantidade muito maior de água do que a quantidade informada oficialmente pelas empresas, no entanto esse consumo não é registrado, pois as empresas captam a água em rios e açudes localizados no interior das fazendas próprias e/ou arrendadas.
} 
A partir da criação dessas políticas, o Estado passou a conceder financiamentos vultosos para a instalação de projetos em diversos setores da economia, como o de celulose e papel.

Em Mato Grosso do Sul, a atuação do Estado, na instância federal, ocorreu, sobretudo, por meio do BNDES, fundamental para viabilizar a estruturação e a expansão do circuito espacial produtivo de celulose, devido aos grandes montantes financiados. Embora existam outros benefícios de caráter mais geral, como, por exemplo, os incentivos físcais concedidos às empresas exportadoras, entende-se que os financiamentos obtidos junto ao BNDES configuram-se como a forma mais clara de relação entre o Estado e as empresas, na instância federal, pois esta se torna nítida devido ao caráter particular e direto dos financiamentos.

A Eldorado Brasil recebeu, por meio de operações diretas e indiretas não automáticas, R\$ 2.713.502.000,00 do BNDES para a implantação da fábrica de celulose branqueada em Três Lagoas e para investimentos sociais nas áreas de influência da empresa, além de mais R\$ 357.980.000,00 para a implantação de monocultivos de eucalipto.Além destes financimentos não automáticos, a Eldorado também recebeu 311 financiamentos por meio de operações indiretas automáticas, totalizando $\mathrm{R} \$ 125.793 .829,00$. Deste modo, somando todos os tipos de operações, a companhia recebeu $\mathrm{R} \$ 3.197 .275 .829,00$ dos cofres públicos.

Em nome da Fibria ${ }^{9}$ e referente à sua atuação direta em Mato Grosso do Sul, o BNDES financiou um total de R \$ 3.850.190.169,00. Desse total, R \$ 833.293.999,00 foram destinados a implantação da primeira linha de celulose branqueada em Três Lagoas e para investimentos sociais em áreas de influência da empresa, e R $\$ 2.300 .000 .000,00$ foram disponibilizados para a implantação da segunda linha de produção de celulose, além de investimentos sociais nas áreas de influência da companhia.

Além destes financiamentos, também foram concedidos cinco financiamentos a FibriaMS Celulose Sul-Mato-Grossense na modalidade "operações indiretas automáticas", totalizando R \$ 36.417.171,00.

Os dados apresentados neste subitem evidenciam que a Fibria e a Eldorado Brasil receberam juntas o montante de $\mathrm{R} \$ 7.047 .465 .998,00$ para o desenvolvimento de ações relacionadas às suas atividades em Mato Grosso do Sul. O que chama a atenção é o fato de a Eldorado, mesmo instalando apenas uma linha de produção, recebeu cerca de $45 \%$ do total financiado, enquanto a Fibria, que instalou duas linhas de produção, recebeu 55\% do total. Tal circunstância pode ser um indício do poder de influência do Grupo JBS junto ao Estado em decorrência do grande montante investido nas últimas eleições.

$\mathrm{Na}$ escala estadual, é essencial entender a importância das políticas criadas pelo governo sul-mato-grossense com o intuito de promover a industrialização e o crescimento econômico estadual. Estas políticas, de caráter mais geral, beneficiaram todos os setores econômicos, no entanto, também foram criadas políticas específicas para o setor florestal, beneficiando o setor de celulose e papel.

A política de incentivos fiscais praticada pelo governo de Mato Grosso do Sul é fundamental para a compreensão do circuito espacial produtivo de celulose no estado, que, inclusive, foi um dos pioneiros na concessão de incentivos fiscais, gerando a "guerra fiscal", ou seja, a disputa entre estados e municípios para receber empresas a partir de isenções e benefícios fiscais.

Santos e Silveira (2001) afirmam que mais do que benefícios fiscais, as empresas buscam lugares que as ofereçam as condições ideais para o desenvolvimento de suas atividades, principalmente no que diz respeito à infraestrutura. Nesse sentido, os autores

\footnotetext{
${ }^{9}$ Considerando a Fibria Celulose S/A (CNPJ 60.643.228/0001-21) e a Fibria-MS Celulose Sul-Mato-Grossense (CNPJ 36.785.418/0001-07).
} 
falam em "guerra dos lugares". Assim, os benefícios fiscais são um componente importante, mas não respondem pela totalidade dos benefícios desejados pelas empresas. Em Mato Grosso do Sul, as empresas de celulose conseguiram esse intento, pois além dos incentivos e benefícios fiscais, também encontraram condições ideais para o desenvolvimento de suas atividades em razão de diversos aspectos, como, por exemplo, a instalação e o melhoramento de sistemas infraestruturais.

O programa Ações para o Desenvolvimento de Mato Grosso do Sul (PROAÇÃO), criado pela Lei $\mathrm{n}^{\circ}$ 1.798/1997, no governo de Wilson Barbosa Martins (1995-1998), marca o início da política sul-mato-grossense de incentivos fiscais. No entanto, o PROAÇÃO foi suspendido pelo Supremo Tribunal Federal (STF) em decorrência de uma ação direta de inconstitucionalidade (ADI) movida pelo governador do estado de São Paulo, Geraldo Alckmin.

Para substituir o PROAÇÃO, foi criado pela Lei ${ }^{\circ}$ 93/2001, durante o mandato de José Orcírio Miranda dos Santos "Zeca do PT" (1999-2006), o Programa Estadual de Fomento à Industrialização, ao Trabalho, ao Emprego e à Renda (MS-EMPREENDEDOR), intensificando a política de investimentos fiscais em Mato Grosso do Sul.

O MS-EMPREENDEDOR visa, por meio de benefícios ou incentivos, fiscais, financeiro-fiscais ou extrafiscais, dinamizar a economia estadual. Segundo Silva (2016, p. 111-112): "o adensamento de cadeias produtivas, qualificação de mão de obra, iniciativas de P\&D e geração de empregos figuram como as principais estratégias nos objetivos do programa". Apesar da nova Lei, o Mato Grosso do Sul continuou a ser alvo de ADIs, o que fez o governo estadual criar a Lei Complementar $n^{\circ}$ 93/2003, estabelecendo novos marcos para a concessão de incentivos ou benefícios fiscais (SILVA, 2016)

Posteriormente, em 2011, o Mato Grosso do Sul instituiu a Lei $n^{\circ} 4.049$, que instituiu o Programa Estadual de Desenvolvimento Industrial MS Forte-Indústria. Em 2013, foi lançado o Decreto $n^{\circ}$ 13.606/2013, que dispôs sobre a prorrogação de benefícios e incentivos fiscais referentes ao ICMS até o final de 2028, o que levou São Paulo a mover nova ADI contra Mato Grosso do Sul em razão de suposta inconstitucionalidade nos benefícios e incentivos fiscais concedidos (SILVA, 2016).

No ano de 2017 entrou em vigor o Decreto $n^{\circ} 14.882 / 2017$, que previa a prorrogação de incentivos ou benefícios fiscais previstos na Lei $n^{\circ}$ 93/2001, além da dispensa da exigência fiscal de créditos tributários.

Além disso, planos foram elaborados pelo governo estadual para legitimar a concessão de benefícios e incentivos fiscais, como o Zoneamento Ecológico-Econômico do Estado de Mato Grosso do Sul (ZEE/MS) e o Plano Estadual para o Desenvolvimento Sustentável de Florestas Plantadas do Estado de Mato Grosso do Sul (PEF/MS). Estes definem, dentre outras diretrizes, áreas prioritárias de investimentos, legitimando ações estatais para beneficiar as empresas que realizam suas atividades no estado em determinados setores econômicos.

O ZEE e o PEF foram lançados no ano de 2009, no primeiro mandato de André Puccinelli (2007-2010), momento em que a primeira agroindústria de celulose entrou em funcionamento e que o circuito espacial produtivo ainda estava em fase inicial de expansão em Mato Grosso do Sul. Neste contexto, era nítido o interesse do governo estadual em legitimar seus investimentos fiscais no setor ligado à produção florestal vislumbrando facilitar a atuação da empresa instalada, além de atrair novas empresas do setor, como foi o caso da Eldorado Brasil.

No aspecto ambiental, além dos dispositivos anteriores, é importante mencionar a Resolução SEMAC/MS no 17/2007 e o Decreto $\mathrm{n}^{\circ} 12.528 / 20008$, criados no governo Puccinelli e responsáveis por flexibilizar a legislação ambiental estadual.

A Resolução SEMAC/MS n 17/2007, em seu Artigo $1^{\circ}$, dispensou o licenciamento ambiental das atividades de 
$\mathrm{EM}$

[...] plantio e a condução de espécies florestais nativas ou exóticas, com finalidade de produção e corte ou extração de produtos florestais diversos, em áreas de uso alternativo do solo com atividade agropecuária, ou em áreas que se encontrem subutilizadas ou degradadas, desde que localizadas fora do Pantanal, das Áreas de Preservação Permanente e de Reserva Legal [...]. (MATO GROSSO DO SUL/SEMAC, 2007).

O Decreto $\mathrm{n}^{\mathrm{o}}$ 12.528/2008 instituiu o Sistema de Reserva Legal (SISREL) no Estado de Mato Grosso do Sul. Esse decreto objetivava assegurar que a cobertura vegetal do território estadual fosse de $20 \%$ no mínimo, mas também contribuiu para a expansão dos monocultivos de eucalipto. Isso porque, conforme seu Artigo $12^{\circ}$, as propriedades rurais que não possuem reserva legal ou que possuem reserva legal inferior a $20 \%$ poderiam formar ou constituir suas reservas com mudas de espécies florestais exóticas, como é o caso do eucalipto (KUDLAVICZ, 2011; PERPETUA, 2012).

A instância municipal diz respeito ao município de Três Lagoas, sede das duas companhias fabricantes de celulose. Seguindo a linha estadual de atração de empresas por meio da concessão de incentivos e benefícios, a Prefeitura de Três Lagoas, nos últimos anos, tem concedidos benefícios fiscais para as empresas que se instalam no município.

Os benefícios estão ligados à Lei $\mathrm{n}^{\circ} 2.467 / 2010$, criada durante o mandato de Márcia Moura (2010-2016), que dispõe sobre a concessão de benefícios fiscais para instalação de indústria no município de Três Lagoas. Estes benefícios estão ligados ao Imposto Predial e Territorial Urbano (IPTU) e ao Imposto Sobre Serviços (ISS) e beneficiaram as empresas que participaram da instalação da primeira linha de produção da Eldorado Brasil e da segunda linha de produção da Fibria. Segundo levantamento realizado em 2017, pelo ex-vereador Jorge Martinho (PSD), Três Lagoas deixou de arrecadar cerca de $\mathrm{R} \$ 300.000 .000,00$ devido à isenção do ISS concedida às empresas que atuaram no projeto de ampliação da Fibria (JP NEWS, 07/10/2017).

\section{Considerações finais}

A combinação dos oito fatores, encontrados somente nesta fração do território, proporcionou a estruturação e, posteriormente, a expansão do circuito espacial produtivo de celulose em Mato Grosso do Sul, sobretudo em sua região Leste. Situação que evidencia que mesmo em tempos de globalização, o lugar ainda tem relevância, sobretudo no que diz respeito aos circuitos espaciais de produção. Essa combinação de fatores também revela uma trama locacional bem articulada, composta por características e elementos naturais e artificiais, a fim de viabilizar o circuito espacial produtivo de celulose na unidade da federação pesquisada.

Os oito fatores, conforme verificado no texto, não se encontram isolados, pelo contrário, são inter-relacionados. A partir dessa combinação de fatores, o circuito espacial produtivo de celulose encontrou condições favoráveis para usar o território corporativamente, submetendo-o a sua lógica, pautada em interesses externos ao lugar e comandada pelas verticalidades do mercado global.

\section{Agradecimentos}

Agradecemos à Coordenação de Aperfeiçoamento de Pessoal de Nível Superior (CAPES) por viabilizar financeiramente o desenvolvimento desta pesquisa. 
EM

QUESTÃO

V.13 N. $01 \bullet 2020$

pág. $82-100$

\section{Referências}

ALMEIDA, R. A. A territorialização do agronegócio do eucalipto na região leste de Mato Grosso do Sul e o cerco à reforma agrária. In:ENCONTRO NACIONAL DE GEÓGRAFOS, XVI, 2010, Porto Alegre. Anais... Porto Alegre: Associação dos Geógrafos Brasileiros, 2010.

BIAZUS, A.; HORA, A. B.; LEITE, B. G. P. Panorama de mercado: celulose. In: BNDES Setorial 32. Rio de Janeiro: BNDES, 2010. p. 311-370. Disponível em: <https://www.bndes.gov.br/SiteBNDES/export/sites/default/bndes_pt/Galerias/Arquivos/conh ecimento/bnset/set32109.pdf>. Acesso em: 13 mai. 2017.

DANTAS, A. Circuito espacial de produção e lugar. Sociedade e Território, Natal, v. 28, n. 1, p. 193-199. jan./jun. 2016. Disponível em: <https://periodicos.ufrn.br/sociedadeeterritorio/article/view/9889/7005>. Acesso em: 15 mar. 2017.

ELDORADO BRASIL. Relatório de Sustentabilidade 2016. (2016) Disponível em: < http://eldoradobrasil.com.br/img/eldorado-rs2017-20170929.pdf>. Acesso em: 06 out. 2017.

FIBRIA. Relatório Fibria 2015. (2015) Disponível em: $<$ http://www.fibria.com.br/r2015/pdf/Fibria_RS2015_20150415.pdf $>$. Acesso em: 12 jan. 2017.

FOLHA. São Paulo: 20/10/2011.Florestas avançam para novas fronteiras. Disponível em: <http://www1.folha.uol.com.br/fsp/mercado/me2010201118.htm>. Acesso em: 15 mai. 2017.

IBGE. Instituto Brasileiro de Geografia e Estatística. Censo Agropecuário (2006). Disponível em: 〈https://sidra.ibge.gov.br/Acervo\#/S/Q〉. Acesso em: 15 mar. 2017.

JP News. Três Lagoas: 07/10/2016. Município deixa de arrecadar milhões com a isenção de ISS para empresas. Disponível em: <https://www.jpnews.com.br/tres-lagoas/municipiodeixa-de-arrecadar-milhoes-com-a-isencao-de-iss-para/102899/>. Acesso em: 18 jun. 2018.

KUDLAVICZ, M. Dinâmica agrária e a territorialização do complexo celulose/papel na Microrregião de Três Lagoas/MS. 2011. 176 f. 2011. Dissertação (Mestrado em Geografia) - Universidade Federal de Mato Grosso do Sul, Três Lagoas, 2011.

MATO GROSSO DO SUL (Estado). SEMAC. Resolução SEMAC n ${ }^{\circ}$ 17, de 20 de setembro de 2007. Disponível em: 〈www.imasul.ms.gov.br〉. Acesso em: 13 dez. 2017.

. Lei $\mathrm{n}^{\circ} 3.839$, de 28 de dezembro de 2009. Institui o Programa de Gestão Territorial do Estado de Mato Grosso do Sul (PGT/MS). Aprova a Primeira Aproximação do Zoneamento Ecológico-Econômico do Estado de Mato Grosso do Sul (ZEE-MS), e dá outras providências. Diário Oficial do Estado de Mato Grosso do Sul, Campo Grande, dez. 2009.

Lei $\mathrm{n}^{\mathrm{o}} 4.049$, de 30 de junho de 2011. Dispõe sobre o Programa Estadual de Desenvolvimento Industrial MS Forte Indústria. Diário Oficial do Estado de Mato Grosso do Sul, Campo Grande, jul. 2011. 
Lei $n^{\circ} 4.285$, de 14 de dezembro de 2012. Dispõe sobre a prorrogação de benefícios e incentivos fiscais concedidos a estabelecimentos industriais, relativos ao ICMS, com base em leis e em outros atos do Poder Executivo, e dá outras providências. Diário Oficial do Estado de Mato Grosso do Sul, Campo Grande, dez. 2012.

Decreto $\mathrm{n}^{\circ} 13.606$, de 25 de abril de 2013. Dispõe sobre prorrogação de benefícios e incentivos fiscais relativos ao ICMS, concedidos a estabelecimentos industriais com base na Lei Complementar $n^{\circ} 93$, de 5 de novembro de 2001, e na Lei $n^{\circ} 4.049$, de 30 de junho de 2011, e dá outras providências. Diário Oficial do Estado de Mato Grosso do Sul, Campo Grande, abr. 2012.

. Decreto $\mathrm{n}^{\circ} 14.882$, de 17 de novembro de 2017. Dispõe sobre a prorrogação de incentivos ou de benefícios fiscais, e sobre a dispensa da exigência fiscal de créditos tributários, nos casos a que se refere a Lei Complementar $\mathrm{n}^{\circ}$ 93, de 5 de novembro de 2001, nos termos das alterações introduzidas pela Lei Complementar $\mathrm{n}^{\circ} 241$, de 23 de outubro de 2017.Diário Oficial do Estado de Mato Grosso do Sul, Campo Grande, nov. 2017.

NARDOQUE, S.; ALMEIDA, R. A. Território Rural do Bolsão (MS): realidade e perspectivas. Boletim Dataluta, n. 85. p. 2-8, jan. 2015. Disponível em: <http://www2.fct.unesp.br/nera/boletimdataluta/boletim_dataluta_1_2015.pdf $>$. Acesso em: 14 out. 2016.

NARDOQUE, S. A relação campo-cidade: abordagem sob o prisma da questão agrária. In: SPOSITO, E. S. (et al). A diversidade da Geografia brasileira. Rio de Janeiro: Consequência, 2016.

OLIVEIRA, F. Crítica à razão dualista - O ornitorrinco. São Paulo: Boitempo, 2003.

O POPULAR. Goiânia: 21/01/2011. Jataí aprova legislação restritiva ao cultivo de canade-açúcar. Disponível em: <https://www.opopular.com.br/editorias/economia/jata\%C3\%ADaprova-legisla\%C3\%A7\%C3\%A3o-restritiva-ao-cultivo-da-cana-dea\%C3\%A7\%C3\%BAcar-1.81340>. Acesso em: 13 mai. 2017.

PERPETUA, G. M. A mobilidade espacial do capital e da força de trabalho na produção de celulose e papel: um estudo a partir de Três Lagoas (MS). 2012. 251 f. Dissertação (Mestrado em Geografia) - Faculdade de Ciências Humanas, Universidade Federal da Grande Dourados, Dourados, 2012.

Pilhagem territorial, precarização do trabalho e degradação do sujeito que trabalha: a territorialização do capital arbóreo-celulósico no Brasil contemporâneo. 2016. 370 f. Tese (Doutorado em Geografia) - Faculdade de Ciências e Tecnologia, Universidade Estadual Paulista, Presidente Prudente, 2016.

SANTOS, M. A natureza do espaço: técnica e tempo, razão e emoção. 4 ed. São Paulo: Edusp, 2006.

; SILVEIRA, M. L. O Brasil: território e sociedade no início do século XXI. 18 ed. Rio de Janeiro: Record, 2014. 
THOMAZ JUNIOR, A. O agrohidronegócio no centro das disputas territoriais e de classe no Brasil do Século XXI. Campo-Território, Uberlândia, v. 5, n. 10, p. 92-122, ago. 2010. Disponível em: 〈http://www.seer.ufu.br/index.php/campoterritorio/article/view/12042/8245>. Acesso em: 13 set. 2017.

TRÊS LAGOAS (Prefeitura). Lei $\mathbf{n}^{\mathbf{0}}$ 2.467, de 08 de outubro de 2010. Dispõe sobre a concessão de benefícios fiscais para instalação de indústria no município e dá outras providências. out. 2010.

.2013. Aeroporto Municipal "Plínio Alarcon". Disponível em: <http://www.treslagoas.ms.gov.br/turistas/aeroporto/38/>. Acesso em: 20 mai. 2017.

Artigo recebido em 04-09-2019 Artigo aceito para publicação em 23-03-2020 